\title{
Research on Internet Financial Regulatory Innovation in China
}

\author{
Yaling $\mathrm{Li}^{1{ }^{1 *}}$ \\ ${ }^{1}$ School of Business and Tourism Management Yunnan University Chenggong District, Kunming, Yunnan, China, 650500
}

\begin{abstract}
As an emerging form of financial innovation, Internet finance will inevitably break through the boundary of traditional finance in the process of innovation. Therefore, how to adapt the supervision to the characteristics of Internet finance and how to balance the innovation and supervision of Internet finance have presented a new issue to the regulatory authorities. Based on the connotation and characteristics of Internet finance, this paper analyzes the current development status of Internet finance in China, and analyzes the problems of Internet finance industry, such as imperfect laws and regulations, chaotic financial supervision institutions, loss of supervision technology and talent, and information disclosure. Finally, from three aspects of supervision legal system, this paper puts forward a series of moderate and effective supervision suggestions on the supervision system and internal supervision mechanism of Internet finance, so as to promote the stable development of the Internet.
\end{abstract}

\section{Introduction}

Since the emergence of Internet finance, it has attracted the attention of various industries and developed rapidly. As an emerging product, academia has also begun to study Internet finance, and different scholars have different perspectives and views. In China, Xie Ping and Zou Chuanwei (2012) put forward the concept of Internet finance for the first time. They believe that modern information technology, especially mobile payments, social networks, search engines and cloud computing, will have a disruptive impact on human financial models. There may be a third financial financing model that is different from either the indirect financing of commercial banks or the direct financing of the capital market, that is, the "Internet financial model". Luo Mingxiong, Tang Ying and Liu Yong (2013) believe that Internet finance is an emerging financial service mode that utilizes a series of modern information science technologies such as Internet technology and mobile communication technology to achieve financial financing. The spirit of "openness, equality, collaboration and sharing" of the Internet has penetrated into the traditional financial industry, exerted a fundamental impact on the original financial model, and created innovative financial service methods derived from it. The financial business forms and financial service modes with the concept and spirit of the Internet are collectively referred to as Internet finance. According to the China Financial Stability Report (2014) released by the People's Bank of China, "Internet finance in a broad sense includes not only the financial businesses conducted by Internet enterprises as non-financial institutions, but also the businesses conducted by financial institutions through the Internet. In the narrow sense, Internet finance only refers to the financial business carried out by Internet enterprises and based on Internet technology.

Based on the comprehensive analysis of the viewpoints of scholars, this paper holds that Internet finance is Internet technology, spirit and finance Industry deep integration of the emerging formats. It is supported by modern information technology such as Internet and mobile communication technology. It integrates the "openness, sharing, collaboration and equality" of the Internet spirit into financial innovation and resource allocation, thus forming a more efficient, convenient, diversified and low-cost financial service model that focuses on customer needs.

In recent years, Internet finance has undoubtedly become one of the topics of concern in today's China. Internet finance is a new product in China, which is the application of computer technology in the financial industry. Internet finance is characterized by low cost, high efficiency and convenience. Therefore, Internet finance has become popular at an unprecedented speed in China. It enables the people who cannot be served by the traditional financial industry to get financing and enriches the financing channels. Internet finance has brought a lot of benefits to people. However, Internet finance is an emerging form of cross-industry financial innovation. Its development in China is still in the primary stage, the various modes are still in the groping forward, the public is still lack of rational understanding of it. Although the government actively supports it, it did not include it in its first government report until 2014. Internet financial regulation is an open subject, which is still in the stage of exploration and progress both at home and abroad.

In essence, the history of the development of world finance is a history of financial innovation and financial crisis. Every major financial innovation has led to a financial crisis. Facts in many developed countries have

*e-mail: 1401321642@qq.com 
proved that the emergence of the financial crisis is more because of the lack of understanding of the risks generated by financial innovation, and the lag or even the absence of financial supervision. Therefore, in order to promote financial innovation for a long time, it is necessary to establish a sound internal risk management procedure and external supervision system. As an emerging form of financial innovation, Internet finance is of course no exception. At the present stage, the development of Internet finance in China is in a stage of frequent risks and imperfect supervision of Internet finance. In the process of its development, many problems have emerged. Therefore, how to conduct supervision of Internet finance has become an urgent problem for us to solve.

Different people have different standards for the classification of Internet finance models. Luo Mingxiong, Tang Ying, and Liu Yong (2013) divided Internet finance into six modes: third-party payment, P2P online lending, big data finance, crowdfunding, information-based financial institutions, and Internet financial portal. However, Xie Ping, Zou Chuanwei and Liu Haier (2014) believe that there are six modes of Internet finance at present: Internetization of finance, mobile payment and third-party payment, Internet currency, P2P network loan, crowd-funding, credit investigation based on big data and network loan. This paper chooses four typical models to analyze and explore, in order to illustrate the development status of Internet finance in China.

\section{The characteristics of Internet finance}

As an emerging financial service model that integrates Internet technology and finance, Internet finance is not a simple mechanical combination of the two industries, but an innovative and deep integration. Therefore, Internet finance has its own unique industrial characteristics. This is the reason why Internet finance can develop at an amazing speed and become the future development trend. Understanding the characteristics of Internet finance is very necessary for the development and supervision of Internet finance.

\subsection{Financial Services Tend to Have a Long Tail}

"The 80-20 law" also reflects the characteristics of China's traditional financial industry. The so-called elite services of China's traditional financial institutions are more inclined to $20 \%$ of the customers in the "20-80 law", while Internet finance aims to win over $80 \%$ of the "long-tail" small and micro customers that are not covered by traditional finance. Due to their relatively low credit, small amount, diversified needs, and the prejudice of traditional financial institutions, it is difficult for these small and micro customers to get financial support. Internet finance combines Internet technology and big data to meet the personalized needs of small and micro customers, which is also the key to make Internet finance have innate advantages in serving small and micro customers. For example, Alipay Wallet, Yu 'ebao, Ant Xiaodai, Shenzhen Qianhai WeBank, P2P online loan, and crowdfunding all solve the investment, financing and loan needs of individual consumers, entrepreneurs and small and micro enterprises to a certain extent. The financing needs of these customers were addressed. The "universality" of Internet finance makes the financial service object no longer just the patent of professionals and large enterprises. So that more "grassroots" consumers and small and micro enterprises can enjoy the benefits of financial services.

\subsection{Financial Services Are More Efficient and Convenient}

The key to the development of Internet finance is that it is inseparable from efficiency and convenience. First of all, information is a vital resource for the financial industry, without which it would be impossible to do anything. The continuous and dynamic information sequence formed by the application of big data and cloud computing of Internet finance can give the risk pricing or dynamic default probability of any capital demander, which enables the information of capital supply and demand to be matched at a high speed, and greatly improves the efficiency of traditional finance. Secondly, Internet finance develops a new network service channel through the use of Internet and wireless communication technology. As long as you have a computer or smart phone, you can handle financial business at home anytime and anywhere, which greatly improves the convenience of financial services.

\subsection{Low Cost and Disintermediation of Financial Services $\mathbf{s}$}

Traditional financial institutions often have high thresholds and huge costs due to network setting and employee compensation. In the Internet financial environment, the information of capital supply and demand can be obtained directly on the Internet, which can greatly reduce the transaction cost. In addition, in the traditional financial industry, customers and providers of funds can only conduct transactions through banks or financial institutions, but the opacity of information makes the cost of funds high for customers. The risk assessment and information processing of Internet finance are based on big data analysis, social network and cloud computing, and carried out through computers. Information can be exchanged, reducing the barriers caused by non-sharing of information, so that the financing cost and risk of customers are reduced. Information sharing is the key factor for the low cost of Internet financial services. The transaction of Internet finance is directly conducted by both parties, and it is separated from intermediate institutions such as banks and financial institutions, which reflects the disintermediation characteristics of Internet finance that are different from traditional finance.

\section{The development status of Internet finance in China}

The year 2013 is the beginning of the rise of Internet finance, Internet financial institutions began to establish one after another. In 2014, the combination of Internet and finance became closer. In this year, Internet finance was 
written into the government report for the first time. The vigorous development of Internet finance aroused the public's attention. The overall status quo can be described as the active support of the government, the development of various models, the giants are racing to get the land, the risks are beginning to emerge, and the supervision is paid attention to. In 2014, the public began to view the development of Internet finance with a relatively rational attitude. People began to think about development prospects, explore regulatory models, and try to construct a good environment for the development of the industry. The following paper will analyze the current situation of Internet finance.

\subsection{Internetization of Finance}

Internetization of finance refers to the transfer of financial activities from offline to online. Compared with traditional finance, Internet finance is more convenient, more efficient, less costly, more transparent and more inclusive. The advantage of Internet finance is that it pays more attention to the needs of capital demanders. These advantages are an important reason why Internet finance is widely accepted and favored by the public. On the basis of their massive customer resources, Internet companies open up new channels of payment, financial management and loan, and step by step deepen financial business. This breaks the privileges of traditional financial institutions such as banks. Faced with the challenges of Internet finance, traditional financial institutions have begun to "connect to the Internet" one after another, such as banks, securities companies, insurance companies, the business of the Internet, online sales channels to provide convenience for customers but also reduce the cost of financial institutions. With the rapid development of Internet finance, traditional financial institutions strive to find their own coordinates mainly through two methods. One is to connect with the Internet more actively. In the process of product development, they are gradually introducing Internet thinking. Second, traditional financial institutions are also strengthening cooperation with Internet companies to make use of them. For example, China Merchants Bank launched the "cloud mortgage", "lightning loan" and other products. In addition, there are more than ten P2P platforms in the banking system, such as Lufax of Ping An Bank, Minsheng Yidai and Mindaitianxia of Minsheng Bank, Qi Le Rong E of Qishang Bank, Kaixin Dai of China Development Bank and so on. Now whether banks, securities companies or insurance companies, they are deeply integrated with the Internet.

\subsection{Third-Party Payment is Thriving}

The boom of online shopping has promoted the progress of third-party payment in China. After more than ten years of development, China's Internet third-party payment has gradually matured. Mobile third-party payment has achieved rapid development. The competition of thirdparty payment companies is still fierce. In order to seek better development, they begin to prepare for offline payment one after another. The $\mathrm{O} 2 \mathrm{O}$ business model is attracting more and more attention. Figure 1 shows the share of online payment scale of Alipay, Tenpay and UnionPay, the three major payment means in China from 2010 to 2019.

The change of payment methods has greatly improved the efficiency of China's payment and played a driving role in improving the efficiency of the overall allocation of financial resources. In the future, the competition for payment will become more intense, and the offline market in the second and third-tier cities and $\mathrm{O} 2 \mathrm{O}$ business environment will become the focus for payment enterprises.

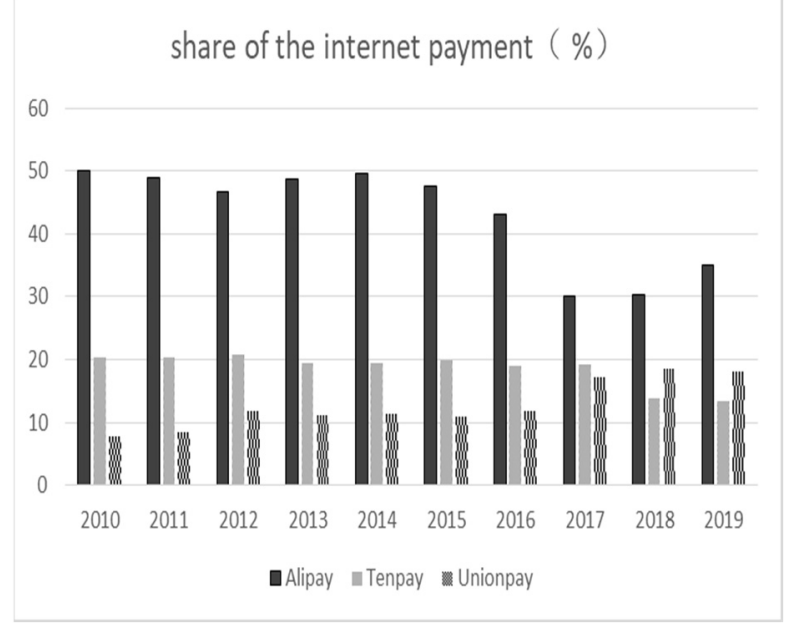

Figure 1. Share of Internet payment scale from 2010 to 2019 Data sources: iResearch Consulting, Analysys think tank

\subsection{P2P Network Loan Explosive Savage Growth}

The development of P2P network lending has been attracting much attention. 2015 years ago, both the number of platforms and the transaction volume of P2P online lending have experienced explosive growth compared with previous years. Many industries are getting involved in P2P. After 2015, the number of P2P online lending platforms and the net loan turnover began to decrease gradually, and it began to decline sharply from 2017. Figure 2 and Figure 3 show the changes in the number of online lending platforms and the transaction volume of online lending in China from 2010 to 2019.

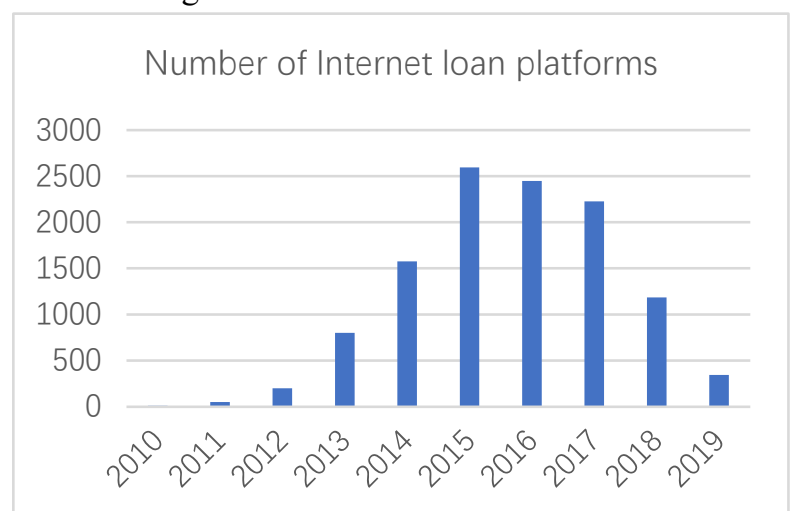

Figure 2. Number of online lending platforms from 2010 to 2019

Data sources: Yingcan Consulting, net loan home, OneZero Data 


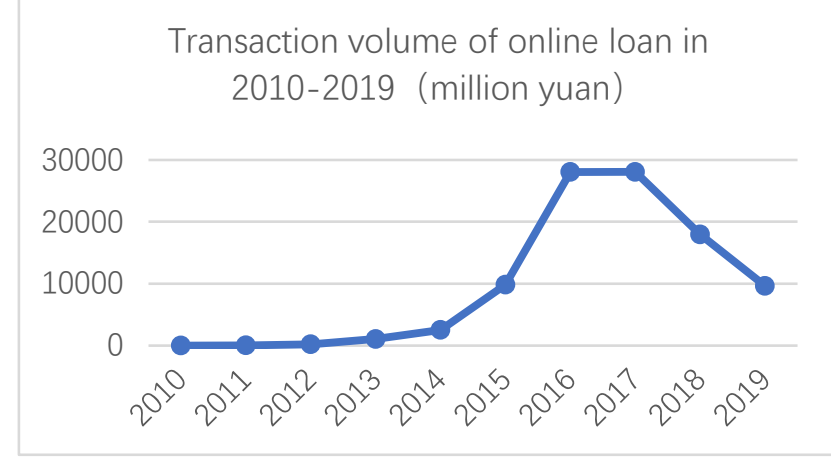

Figure 3. Transactions of online loans from 2010 to 2019 Data source: net loan home

However, with the development of Internet finance, there are many problems such as "running away", "fraud", "withdrawal difficulty", malicious attack by hackers, and so on. People also have many doubts about the P2P industry. The frenzied growth of P2P appears to have put some small platforms out of business. After several years of standardized development and reshuffle, the situation has improved. The number of problematic platforms in 2019 is significantly lower than in 2015. See Figure 4.

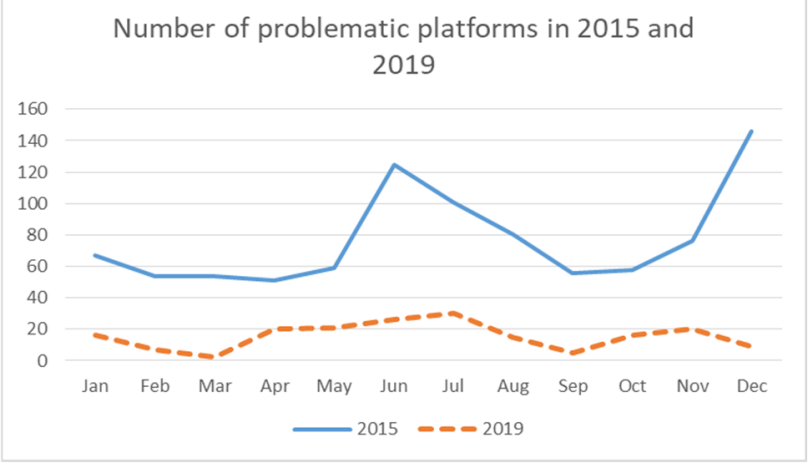

Figure 4. Number of problem platforms in 2015 and 2019 Data source: Wangdaizhijia, zhongshen net

P2P, as a new financial innovation model, is conducive to the sunshine of China's private finance and improve the financing problems of small and medium-sized enterprises and personal loans. It is a beneficial supplement to our traditional finance. However, China's P2P platforms are still in the stage of wild growth. We should ensure the innovation and vitality of the industry while implementing regulatory details as soon as possible. In this way, risks can be controlled and the healthy development of P2P industry can be regulated.

\subsection{The Crowdfunding Industry is Booming}

Crowdfunding usually refers to a financing method in which the project initiator takes advantage of the communication characteristics of the social network of the Internet to mobilize the power of the public and concentrate the public funds to provide necessary financial assistance for small enterprises, creative artists or individuals to carry out a certain activity or project or establish an enterprise. As an emerging mode of financial innovation, crowdfunding has the advantages of innovation and low financing threshold. For fund-raisers, they have access to future consumers' money without incuring any costs, and they can test the popularity and market prospects of the product and project design by the number of contributors. This saves a lot of money compared to spending money up front and having to rethink the idea after the product doesn't sell or the project fails. For consumers, they can get in touch with producers before the products they are interested in come out, and they have the opportunity to get the latest products.

\section{Problems in the supervision of Internet finance}

Internet finance, due to its innovation in the traditional financial model, has made up for the deficiency of the original financial model. But along with some of the problems are gradually revealed. In recent years, problems such as running away from online lending platforms have been reported frequently, which gradually arouse people's attention and start to pay attention to the supervision of Internet finance model. Now it is urgent to build a regulatory system of Internet finance. In order to promote the healthy development of Internet finance, regulatory authorities have introduced a series of measures, which have played a positive role in the development of Internet finance. However, there are still a series of problems, which are difficult to meet the needs of the development and management of Internet finance. These problems are mainly manifested in the following aspects:

\subsection{The Supervision and Regulation of Internet Finance is Not Perfect}

On the one hand, we lack specialized laws and regulations. The current financial laws and regulations in China are mainly based on the traditional financial model, which cannot meet the supervision needs of Internet finance. There are no corresponding laws and regulations on the market access standards and information protection of Internet finance. For example, for the management of third-party payment institutions, only the central bank involves the access management of third-party payment institutions in the payment service management measures of non-financial institutions, and there are no special laws and regulations for the Internet financial model to regulate it. At present, the scale of Internet finance is already large. Some risk events continue to appear, such as account funds stolen, cash out, personal information leakage phenomenon. The original financial supervision system has been unable to effectively maintain financial stability and financial order. Protecting the rights and interests of financial consumers and punishing illegal crimes in a timely manner is a major problem facing the choice of Internet financial supervision mode. Therefore, it is necessary to speed up the construction of Internet financial supervision system to meet the needs of the development of Internet finance.

On the other hand, Internet finance supervision legislation lags behind. Due to the rapid development of Internet finance, Internet finance technology is often ahead of supervision, which makes some provisions in 
existing laws and regulations unable to meet the development needs of the industry, and Internet finance supervision legislation in China is slightly lagging behind and rigid. Taking P2P network lending as an example, P2P network lending deviates from the intermediary nature of P2P network lending platform in many aspects during its operation. For example, its current business model, such as capital pool, intermediary trading and platform guarantee, is often in the gray area of supervision, which needs to be regulated by relevant regulatory rules.

\subsection{The Regulatory Body of Internet Finance is not Clearc}

In Many models of Internet finance are characterized by mixed operation. A financial model often involves several industries, and its business scope has expanded from simple payment business to traditional banking services such as transfer and remittance, credit card repayment and so on. Internet finance is in urgent need of a professional and unified regulatory institution due to its multiple business models and cross-border nature. However, such an institution does not exist at present. At the present stage, China still continues the traditional financial supervision system of separate operation and separate supervision. The main division of labor is the supervision of the third-party payment business by the People's Bank of China. The CBRC is responsible for the supervision of the business of $\mathrm{P} 2 \mathrm{P}$ online lending platforms. The CSRC is responsible for the supervision of third-party securities and fund sales business. In this mode of separate supervision, there is a lack of coordination among various regulatory agencies in the process of supervision. As independent regulators, each agency is in charge of its own, which leads to the increase of regulatory costs. In addition, Internet financial models are basically characterized by mixed operation, which will also make some financial models outside the regulatory system. For example, Internet financial management institutions are mainly subject to the daily management of industrial and commercial departments. However, due to the typical financial properties of Internet financial management, no financial regulatory authorities have explicitly included it into the scope of supervision under the current separate financial supervision model. Another example is financial products such as Yu 'ebao, which combine third-party payment and interrelated Internet financial products of monetary fund. It seems that the supervision of "one line and three meetings" by any party alone may cause crossover problems.

\subsection{The Division of Responsibilities of Financial Regulators of Internet Finance is not Clear}

Many models of Internet finance have the characteristics of mixed operation, and a financial model often involves several industries. Its business scope has also expanded from simple payment business to traditional banking services such as transfer and remittance, credit card repayment. It is difficult for the existing model of Internet finance to be effectively supervised by the original model of separate supervision. At present, there is a lack of clear division of responsibilities and identification of responsibilities among the People's Bank of China, China Banking Regulatory Commission, China Securities Regulatory Commission and China Insurance Regulatory Commission. At the same time, the separate supervision mode also lacks the coordination among regulators, which leads to the lack of clear supervision subject and division of responsibilities in the financial business carried out by Internet enterprises. It is difficult for relevant financial businesses to be regulated in the corresponding regulatory system according to the principle of separate management, resulting in some regulatory vacuum.

\subsection{Monitor Technology and Talent Gaps}

Compared with the traditional financial industry, the Internet finance industry faces greater risks in the development process of Internet finance due to its high technical content, wide coverage and fast propagation speed. For example, the existence of loopholes in the Internet system and other problems will lead to the disclosure of information, which may infringe the rights and interests of various participants and pose new challenges to the innovation of technical methods and means for supervision. Internet finance has the advantages of convenience and quickness. However, in the absence of supervision at present, the simple pursuit of convenience and quickness often leads to neglect of technical loopholes, resulting in malignant events such as information leakage. Internet finance is a technology-intensive industry. China's regulatory technology is backward and there is a lack of talents. The development speed of the regulatory team is far from keeping pace with the development pace of Internet finance.

\subsection{Information Leakage Problem}

Because of the particularity of Internet finance, its transaction process is basically carried out on the Internet. The two parties trade through an online platform. Both parties only need to transfer information and money through their respective computer terminals. Both parties transact transactions through the Internet, including ID card number, mobile phone number and other user identity information as well as account information and fund information. Therefore, Internet finance has a large amount of customer information. Due to the hidden risks in the Internet communication system and Internet technology, there may be the risk of information leakage in the process of trading. At the same time, due to management negligence or technical defects and other reasons, the trading platform may also have the risk of information being illegally stolen or even tampered with. Personal information security is the most concerned part of every consumer. Once information leakage occurs, the public will have a crisis of trust in the system security of payment institutions, which will further affect the healthy development of Internet finance and even the whole society. Therefore, the primary risk of Internet finance is the risk of information leakage, and China's regulatory authorities should pay attention to it. 


\section{Suggestions on supervision of Internet finance}

\subsection{Improve Regulatory Laws and Regulations}

Due to the international nature of Internet finance, China can timely supplement and amend the laws related to Internet finance supervision based on the existing legal framework according to the development characteristics of domestic Internet finance, referring to the international legislative experience, and making clear provisions on the rights and obligations of all parties involved. Internet finance in China is still in the primary stage of development. It has not been tested by the economic cycle, so the relevant legislation should be explored and advanced. In the early stage of legislation, laws of lower rank can be adopted to timely discover the legal deficiencies in the operation of the industry. In this way, we can make adjustment and regulation, and avoid the consequence of blocking the development and innovation of Internet finance caused by high legislative rank and excessive efforts. For mature models and laws and regulations in line with the direction of industrial development, a higher level of law can be considered. Second, the legal system should also keep pace with The Times.

For those laws and regulations that lag behind the development of Internet finance and hinder the development of emerging business forms, reform and update should be made in time. For example, Internet finance often involves issues such as securities issuance, limit on the number of investors and illegal fund-raising. As for the above problems, the innovation and development needs of Internet finance often have frictions with the existing laws and regulations. The regulatory authorities should consider whether certain legal provisions have become factors hindering social and economic development and make timely reforms.

Take crowd-funding regulation as an example, if the traditional regulation method is adopted and the regulation is carried out through the restriction of the number of investors, it will seriously violate the characteristics of crowd-funding with small amount of public funds. Chinese can refer to the JOBS Act of the United States, which controls the equity and total capital of crowdfunding through a single amount of capital, rather than the traditional restriction on the number of people. A new balance has been found between encouraging the development of crowdfunding and protecting the rights and interests of consumers and preventing speculation. In addition, there are regulatory gaps in some areas of Internet finance in China, which are not covered by existing laws. In this regard, the regulatory authorities should introduce and implement relevant laws and regulations as soon as possible to prevent and control risks, and to avoid the situation that can not be followed once the risk problems appear. Take the P2P industry as an example, although the government gave red lines, principles and guidelines in 2014. However, the specific regulatory rules have not been issued, and the regulation is basically in a blank state. In the face of the outbreak of P2P industry risk events. If the regulation is not rolled out in time, some investors will gradually lose confidence in the P2P industry. It will hinder the further development of the industry. So the clear introduction of relevant laws and regulations is an urgent problem to be solved.

\subsection{Improve the Industry Access System and Withdrawal Mechanism}

Industry access system is the first line of defense for institutions to enter the industry. Only institutions with prescribed conditions are qualified to enter the market. At present, China's Internet finance platforms are uneven in quality, which is directly related to the lack of access system in China. For example, there is no industry access requirement for $\mathrm{P} 2 \mathrm{P}$ platforms in China. As long as there is a platform website system, it can be easily entered, which leads to the existence of many substandard small platforms in China's P2P industry. Therefore, China should perfect the industry access system and set the threshold. Through the establishment of access system to avoid some unqualified institutions to enter the market. The entry threshold can be set according to the characteristics of different Internet finance modes and the regulatory needs of different operation modes. The entry threshold specifies the qualification of employees, technical safety qualification, registered capital, risk control ability, business scope and internal system construction of the institution. In this way, it can ensure that the institutions entering the industry have good credit, strong technical and management teams, high-quality practitioners, and strict internal control. An institution license may be granted to an institution that meets the requirements. This can effectively do a good job of source supervision, so as to prevent the disorderly development of institutions. In order to protect the stable and healthy development of Internet finance, while improving the market access system, the corresponding market exit mechanism should be established to realize the natural integration of the market and the survival of the fittest. The orderly and efficient development of Internet finance can only be promoted by the introduction of exit mechanism and timely elimination of unqualified institutions.

\subsection{Build a Multi-Level Internet Finance Supervision System}

Internet finance is the deep penetration of Internet technology into the financial industry. Its cross-industry and cross-region characteristics pose a huge challenge to the separate supervision of traditional finance in China. Therefore, China should build a multi-level supervision system of Internet finance, and achieve a multi-level supervision system that combines central supervision with local supervision and government supervision with selfdiscipline organization supervision, so as to avoid duplication and blank phenomenon in supervision.

First, central and local supervision should be combined. At present, the local supervision of Internet finance has gone ahead of the central supervision. China's central regulatory authorities should implement the detailed 
regulations as soon as possible and provide a unified standard for the supervision of Internet finance. Local governments should formulate regulatory rules suitable for the development and risk characteristics of local Internet finance based on the characteristics of each region and the unified regulatory standards of the central government.

Secondly, we should give full play to the role of the industry self-regulatory organizations, strengthen the industry self-regulatory management, and urge members to implement the laws and regulations and the industry uniform standards and self-regulatory conventions set by the self-regulatory organizations. It can protect consumers, prevent risks, maintain market order and promote the healthy and sustainable development of the industry.

In addition, communication and coordination between regulatory authorities should be strengthened. We should establish a coordination mechanism for financial supervision as soon as possible, clarify the division of labor and responsibilities of regulatory authorities, and strengthen information sharing and supervision coordination among regulatory authorities. We should avoid regulatory vacuum and duplication, prevent regulatory arbitrage, and improve regulatory efficiency.

Finally, due to the international characteristics of Internet finance, China should strengthen exchanges and cooperation with foreign regulatory authorities. We will implement unified

\subsection{Change Gradually From Institution Supervision to Function Supervision}

At present, China implements the financial supervision mode of separate operation and separate supervision. With the People's Bank of China as the core, the Banking and Insurance Regulatory Commission and the China Securities Regulatory Commission are respectively responsible for institutional supervision of the banking, insurance and securities industries. However, the mixed operation trend of China's Internet finance is very obvious, and there are certain contradictions and frictions with China's institutional supervision, and it is easy to appear the situation of regulatory arbitrage and inconsistent standards. For example, Alibaba's $\mathrm{Yu}$ 'e Bao is an innovative product that combines third-party payment with money market fund. It involves not only banking business, but also securities business. There are disputes over which type of institutions should it belong to, and whether it should be supervised by CBRC or CSRC. Therefore, Internet finance should be regulated innovatively and keep pace with The Times, so as to adapt to the development characteristics of Internet finance, and gradually transition from institutional supervision to functional supervision. Functional supervision is based on the nature of business and risk types to divide the regulatory objects. Different Internet financial institutions, as long as they operate the same business and generate the same risks, should be subject to the same regulation. The regulatory rules and standards for functional supervision do not differ according to the type of institution. Functional supervision is conducive to the implementation of unified regulatory standards for Internet finance and to prevent the emergence of regulatory arbitrage and regulatory vacuum. In order to promote the healthy and sustainable development of Internet finance, the regulatory authorities should accelerate the pace of transformation of regulatory methods to promote the development of regulation.

\section{Summary}

In short, Internet finance, as an emerging form of financial innovation, will inevitably break through the boundary of traditional finance in the process of innovation. Therefore, how to adapt the supervision to the characteristics of Internet finance and how to balance the innovation and supervision of Internet finance have presented a new issue to the regulatory authorities.

First of all, we should affirm that Internet finance has a very positive effect on both China's finance and the real economy. Therefore, we should provide space for innovation and development, so as to improve the competitiveness and universality of China's financial industry. We will provide more diversified and personalized financial services. We should provide more financing channels for small and micro customers.

Secondly, on the premise of supporting and accommodating the development of the Internet finance industry, the relationship between innovation and regulation should be properly handled, so as to promote development through regulation and avoid excessive regulation hindering the development of the industry. The supervision of Internet finance should be based on the protection of the legitimate interests of the public. For the purpose of risk prevention, we should make clear the legal red line and stick to the bottom line, build a good highvoltage line, speed up the legislative process, provide a good legal environment for the development of the industry, and make the regulation have laws to follow.

In addition, as Internet finance is the product of the combination of computer and finance, both business and risk have their own characteristics. Therefore, supervision should adapt to the development characteristics of Internet finance. The trend of mixed operation of Internet finance is obvious. This has certain friction with our country's institutional supervision and division supervision. Therefore, this paper puts forward the viewpoint of gradually changing from institutional supervision to functional supervision.

In general, the principles of moderate supervision, classified supervision, innovative supervision and cooperative supervision should be adhered to.

\section{References}

1. Mary J. Cronein . Banking \& Finance on the Internet [M] .2002: 133-156

2. Allen F.E-Finance : An Introduction. Journal of Financial Serrices Research.2002, 22(1/2):5-27 
3. Scholtens B. And Wensveen D.V. The Theory of Financial Internediation: An Essay On What It Does (not) Explain .Working Paper.2003.

4. Berger S. and F. Gleisner .mergence of Financial Intermediaries on Electronic Markets : The Case ofonline P2P Lending. Working Paper. University of Frankfurt .2008.

5. Xie Ping, Zou Chuanwei. Research on Internet Finance Mode [J]. Financial Research, 2012,(12):1122.

6. Zhang Fen, Wu Jiang. The regulatory experience of foreign Internet finance and its enlightenment to China [J]. Finance and Economics, 2013(11).

7. Wu Zhiguo, Song Pengcheng, Zhao Jing. Capital Market Regulation: The Art of Balance: The Enlightenment of Crowdfunding Regulation in America [J]. Financial Review,2014 (3).

8. Wang Aijian. Promoting the healthy development of Internet financial norms [N]. Financial Times 2014-310 (11).

9. Zhou Xiaoyuan. Online financial supervision should not be slow $[\mathrm{N}]$. People's Daily Overseas Edition, 2014-6-13 (02).

10. Lu Zhengcommar. Internet Finance: the Balance between Encouraging Innovation and Improving Regulation [N]. 21st Century Business Herald 2014-3-17 (23). 